\title{
Associations between Online Addiction, Attachment Style, Emotion Regulation, Depression and Anxiety in General Population: Testing the Proposed Diagnostic Criteria for Internet Addiction
}

\author{
Ebubekir Ceyhan ${ }^{1}$, Murat Boysan²*, Muhammed Tayyip Kadak ${ }^{3}$ \\ ${ }^{1}$ Sason Vocational College, Batman University, Batman, Turkey \\ 2Department of Psychology Faculty of Social Sciences Van Yüzüncü Yıl University, Van, Turkey \\ ${ }^{3}$ Department of Child and Adolescent Psychiatry, Cerrahpaşa Faculty of Medicine, Istanbul University, Turkey
}

\begin{abstract}
The focus of this study was twofold. The first aim of the study was to investigate psychometric properties of the Turkish version of the Chen Internet Addiction Scale (CIAS). Second, we explored the relations between Internet Addiction, Attachment Style, Emotion Regulation, Depression and Anxiety among college students. A total of 754 college students participated in the study. The CIAS, Young Internet Addiction Test (YIAT), Experiences in Close Relationship-Revised (ECR-R), Difficulties in Emotional Regulation Scale (DERS), Center for Epidemiological Studies Depression Scale (CES-D), Beck Anxiety Inventory (BAI), and WHO Disability Assessment Schedule 2.0 (WHODAS 2.0) were administered in the study. The CIAS was subjected to confirmatory factor analysis. The associations between Internet addiction, attachment styles, difficulty in emotion regulation, anxiety and depression were evaluated using one-way analysis of variance and logistic regression analysis. The signal detection analysis showed that a cut value of 64 for the CIAS, with diagnostic accuracy of $97.1 \%$ and a cut value of 40 for the YIAT, with diagnostic accuracy of $86.9 \%$ were evaluated to be best diagnostic cutoff points. Considering univariate relationships between variables of interest, fearful and preoccupied attachment were significantly associated with pathological Internet use. Logistic regression analyses demonstrated that being male, difficulties in emotional regulation, anxiety and depression statistically significantly contributed to the risk for development of Internet addiction. Internet addiction as indexed by the CIAS cutoff is a highly debilitating mental disorder.

Keywords: Behavioral addiction, affect regulation, addictive behaviours, diagnostic accuracy, assessment, confirmatory factor analysis, psychopathology
\end{abstract}

\section{INTRODUCTION}

Over the last two decades, the research on Internet use

\footnotetext{
*Correspondence: boysan.murat@gmail.com

Murat Boysan, PhD, Department of Psychology Faculty of Social Sciences

Van Yüzüncü YIl University, 65100 Van/ Turkey

Telephone: +90 432 2251051/232 11
}

Received: 06 April 2018 Accepted: 01 May 2018

\section{Sleep and Hypnosis \\ Journal homepage: \\ www.sleepandhypnosis.org \\ ISSN: 2458-9101 (Online)}

disorders and its antecedents has grown significantly (Cash, Rae, Steel, \& Winkler, 2012; Kuss \& LopezFernandez, 2016; Pontes, Kuss, \& Griffiths, 2015; Spada, 2014; Suissa, 2015). In the recent revision of the Diagnostic and Statistical Manual (DSM-5), Internet gaming disorder has been included as a clinically important condition that needs more research (American Psychiatric Association, 2013). Nevertheless, potential online addictions such as gambling, pornography, cybersex, social networking, shopping seem to have comparable detrimental effects, suggesting that limiting a 
diagnosis to online gaming would result in missing out many cases of individuals experiencing severe impairment due to online addiction (Lopez-Fernandez, 2015).

The scope of the conceptualization of Internet use disorders varies substantially and includes symptoms derived from pathological gambling or substance-related addiction. Griffiths' addiction components (2005) include salience, mood modification, tolerance, withdrawal, conflict, and relapse. Tao et al. (2010) put forward eight dimensions of Internet addiction disorder as preoccupation, withdrawal, tolerance, difficulty to control, denial of harmful outcomes, impairment in social functioning, mood alterations and concealment. In the DSM-5 nine symptoms of preoccupation, withdrawal, tolerance, loss of control, continued use, neglect of alternative activities, escapism and mood modification were suggested and stipulated five or more symptoms over a 12- month period were stipulated to meet Internet Gaming Disorder (APA, 2013). In extensive reviews, scholars have identified different assessment instruments relevant to Internet addiction and concluded that three principal diagnostic assessment approaches include Young's Internet Addiction Diagnostic Questionnaire (YIADQ) (K. S. Young, 1998) and Internet Addiction Test (YIAT) (K. Young, 1998), Chen Internet Addiction Scale (CIAS) (Chen, Weng, Su, Wu, \& Yang, 2003), with miscellaneous cutoff values for classification (Aboujaoude, 2010; Kuss, Griffiths, Karila, \& Billieux, 2014). As mentioned, demarcation points utilized for classification of Internet use disorders differ substantially and the issue conveys difficulties establishing a gold standard for a reliable diagnosis and identifying more firmly the underlying etiological factors (M. D. Griffiths et al., 2016; Kuss et al., 2014; Kuss \& Lopez-Fernandez, 2016).

In an attempt to develop diagnostic criteria for Internet addiction, Ko, Yen, Chen, Chen, and Yen (2005) proposed 13 candidate criteria including preoccupation, craving, tolerance, withdrawal, Internet use longer than intended, losing control over Internet use, excessive time spent online, excessive effort spent on activities, and continued overuse despite physical and psychological problems, accompanied by functional impairment in work or school, social relationships and violations of school or community rules over a three months time. Presence of six or more symptoms in B criteria alongside functional impairment in at least one domain was stipulated for a principal diagnosis of Internet addiction. The Diagnostic Criteria of Internet Addiction (DC-IA) was empirically tested on the basis of a systematic psychiatric interview and showed an excellent diagnostic accuracy, with high specificity (97.1\%) and sensitivity (87.5\%). In further studies, the DC-IA was utilized to detect optimal cutoff for the CIAS. The CIAS yields total scores ranging from 26 to 104, and a cutoff value of 64 was demonstrate to have excellent diagnostic accuracy and specificity (87.6\% and $92.6 \%$ ) based on the results of systematic diagnostic interviews relying on the DC-IA (Ko, Yen, Yen, et al., 2005). In a replication study, a two stage diagnostic approach using the DC-IA and the CIAS with an optimal cutoff 64 was attested to be discriminative for Internet addiction among college students (Ko, Yen, Chen, Yang, et al., 2009).

There has been ample evidence that emotion regulation process causally involve in psychopathological conditions including addictions (Schreiber, Grant, \& Odlaug, 2012). Despite the complexity of the construct, some conceptualizations concerning emotion regulation include identification and expressive control of emotional experiences, modulation of aroused states, and directing behaviours in socially acceptable ways (Aldao, NolenHoeksema, \& Schweizer, 2010; Gratz \& Roemer, 2004; Linehan, 2014). More recent models of Internet use disorders has postulated that the underlying etiological factors pertaining to specific behavioral addiction can be best understood as outcomes of interactions of biopsychological predisposing factors with affective, cognitive and executive functioning mediated via coping capacity, attentional and cognitive biases (Brand, Young, \& Laier, 2014; Brand, Young, Laier, Wolfling, \& Potenza, 2016; G. H. Dong \& Potenza, 2014). Co-occurrence and significant linkages of attention deficit and hyperactivity disorder traits, anxiety, social phobia, various psychosomatic health complaints and depression with Internet addiction disorders seems to be norm rather than exception (Cho, Sung, Shin, Lim, \& Shin, 2013; Gamez-Guadix, 2014; D. A. Gentile et al., 2011; Ko et al., 
2014; Ko, Yen, Chen, Yeh, \& Yen, 2009; Siddiqui, Qureshi, \& Alghamdi, 2018) that the significant associations between mental health and addictive Internet use disorders appear to be bi-directional (Anderson, Steen, \& Stavropoulos, 2017; Ciarrochi et al., 2016; G. Dong, Lu, Zhou, \& Zhao, 2011; Gamez-Guadix, Orue, Smith, \& Calvete, 2013; van den Eijnden, Meerkerk, Vermulst, Spijkerman, \& Engels, 2008). High comorbidity of psychiatric disorders which is indicative of greater difficulties in emotion regulation may contribute to a more complicated manifestation of symptoms, more treatment difficulties and poor prognosis of addictive disorders (Benaiges, Prat, \& Adan, 2010). Moreover, addictive behaviours may be regarded as counterproductive strategies to gain relief in response to negative emotional states (Al-Gamal, Alzayyat, \& Ahmad, 2016; Boysan et al., 2017; Brand, Laier, \& Young, 2014; Cheng, Sun, \& Mak, 2015; Chou et al., 2015; Hormes, Kearns, \& Timko, 2014; Kardefelt-Winther, 2017; Kuss, 2013; Li et al., 2016; Zhou, Li, Li, Wang, \& Zhao, 2017) and an ability to executively differentiate, understand and regulate emotions has been suggested to be central in managing addictive behaviours (Brand, Young, et al., 2014; Kun \& Demetrovics, 2010).

The emerging evidence concerning the significant relations between online addictive behaviours and emotion regulation was that pathological Internet use appears to serve as a form of mood regulation strategy that leads to severe impairment in mood regulation (Billieux \& Van der Linden, 2012). Internal and external emotion dysregulation were found be significantly associated with addicted behaviors in terms of pathological Internet and smart phone use amongst high school student (Yildiz, 2017); while difficulties expressing emotions was a significant antecedent of addictive Internet use among college students (Oktan, 2011). In comparison to normal controls matched for age, gender and education, individuals with gaming disorder were more likely to use maladaptive emotion regulation strategies in terms of lower cognitive reappraisal and higher expressive suppression, and revealed greater depression, anxiety and hostility (Yen et al., 2018). Using the Affective Neuroscience Personality Scales, a self- report measure of primary emotions, fear and sadness were demonstrated to be robust antecedents of different aspects of problematic Internet use in a community dwelling sample (Montag, Sindermann, Becker, \& Panksepp, 2016). Spada and Marino (2017) tested a structural model and indicated that meta-cognitions and emotional regulation impacted separately on problematic Internet use among 380 youngsters, aged 13 to 20 . In a more recent surveillance of problematic Internet use, Akbari (2017) identified that college students who had lower distress tolerance were more likely to escape through mobile devices or computers to gain relief. Difficulties in emotion regulation had indirect impact on problematic Internet use via meta-cognitions and distress tolerance.

Attachment is a strong emotional bond within people originates from early experiences with parents, including warm, intimate and stable relationship between parent and infant (Bowlby, 1988). Brennan, Clark, and Shaver (1998) suggested a two dimensional construct of adult attachment, i.e., attachment anxiety and attachment avoidance. Attachment anxiety refers to the fear or anxiety of being abandoned and attachment avoidance is marked by discomfort of intimacy and reliance. Based on these two principal aspects of attachment, four dimensional model of attachment styles includes secure attachment characterized by low levels of anxiety and avoidance, avoidant marked by high levels of avoidance, preoccupied with high levels of attachment anxiety and fearful characterized by high levels of both attachment anxiety and avoidance (Bartholomew \& Horowitz, 1991). From the view of stress diathesis perspective, insecure attachment is associated with difficulties in emotion regulation which cannot be regarded as psychopathology per se rather seems to be a robust vulnerability for development of psychological disorders (Boysan \& Çam, 2016). With respect to the relations between attachment and addiction, Flores (2004) posited that addictive behaviours can be regarded as a counterproductive strategy in dealing with emotion regulation problems emerged from attachment insecurities.

There has been a growing research interest on associations between online addictive behaviours and 
attachment styles. Attachment insecurities seem to exert influence on online interpersonal behavioral patterns that insecurely attached individuals have less likely expand their social networks and social ties (Jenkins-Guarnieri, Wright, \& Hudiburgh, 2012; Lee, 2013), are concerned about their perceived images (J. H. Lin, 2015, 2016) and reveal less interest in social networks (Liu, Shi, Liu, \& Sheng, 2013; Oldmeadow, Quinn, \& Kowert, 2013). Nevertheless, attachment insecurities particularly attachment anxiety were significantly associated with fear of missing in online relations that predicted more frequent social media use (Blackwell, Leaman, Tramposch, Osborne, \& Liss, 2017). On the other hand, Internet addicts has consistently been found to have a tendency towards insecure attachment (M. P. Lin, Ko, \& Wu, 2011; Monacis, de Palo, Griffiths, \& Sinatra, 2017a, 2017b; Schimmenti, Guglielmucci, Barbasio, \& Granieri, 2012; Severino \& Craparo, 2013) that preoccupied and dismissive attachment styles were reported to be significant correlates of online addictive behaviours (Odaci \& Cikrikci, 2014; Savci \& Aysan, 2016). An interaction of avoidant and anxious attachment with psychopathology in terms of depression and phobia contributed to undue Internet use in which depression moderated the relations between attachment avoidance and addictive behaviours, leading to future alcohol dependency (Shin, Kim, \& Jang, 2011). The emerging evidence has consistently pointed out that both paternal and maternal attachment insecurities were significant antecedents of development and persistence of online addictive behaviours (Kim \& Kim, 2015; Lei \& Wu, 2007). Family environment plays a central role in protection against and an increased risk for development of addictions that marital conflict was indicated to have a significant influence on decreased paternal and maternal attachment as well as peer attachment that lead development of behavioral addiction (Yang, Zhu, Chen, Song, \& Wang, 2016). In a study conducted among 310 high school students, Schimmenti, Passanisi, Gervasi, Manzella, and Fama (2014) found that adolescents addicted to Internet use were more likely to report childhood physical and sexual traumatic experiences, as well as greater scores on three types of attachment insecurities in terms of need for approval, preoccupation with relationships and avoidant attachment compared to non-addicted individuals. However, once the shared variances were controlled for the predictor variables of interest, preoccupation with relationship coupled with early traumatic experiences were still contributing to the risk for addictive behaviours.

In this study it was aimed to study several aspects pathological Internet use. First, establishing a reliable diagnostic criteria for online addictive behaviours is critical to firmly understand the underlying etiological factors and develop more effective interventions. To this end, we assessed diagnostic accuracy of the cut point on the CAIS originally proposed by Ko et al. $(2005 ; 2005$; 2009) concurrent with functional impairment as indexed by WHODAS 2.0 (Üstün, Kostanjsek, Chatterji, \& Rehm, 2010). Second, using signal detection analysis, the optimal cut value of the YIAT corresponding to the demarcation point on the CAIS was explored. Third, the predictive values of attachment styles and difficulties in emotion regulation along with anxiety and depression on pathological Internet use were investigated.

\section{METHOD}

\section{Participants and Procedure}

Participants were seven hundred fifty-four college students, aged from 17 to 50 . Participants' average age was 20.82 \pm 3.31 years. Almost half of the sample were female $(n=416,55.2 \%)$. Volunteers reported average $3.4 \pm 2.8$ hours daily Internet use. Socio-demographic characteristics of the sample are presented in Table 1.

In order to obtain the Turkish version of the CIAS, a standard translation protocol was adopted. All 26 items were underwent a preliminary English to Turkish translation by two scholars. After comparing the translated versions of the Turkish CIAS, a final Turkish form of the questionnaire was achieved by matching both translated versions.

The study was undertaken at Batman University among undergraduates enrolled in various programs. The scope, purposes, and procedure of the current investigation were announces in the classes. Volunteers 
Table 1. Descriptive statistics for the demographic characteristics of the sample $(\mathrm{N}=754)$

\begin{tabular}{|c|c|c|c|c|}
\hline Age & & (Mean, SD) & 20.82 & 3.31 \\
\hline Daily Internet use (hours) & & (Mean, SD) & 3.38 & 2.76 \\
\hline \multirow{2}{*}{ Gender } & Male & $(n, \%)$ & 338 & 44.83 \\
\hline & Female & $(n, \%)$ & 416 & 55.17 \\
\hline \multirow[t]{3}{*}{ Income } & Low & $(n, \%)$ & 106 & 14.06 \\
\hline & Average & $(n, \%)$ & 615 & 81.56 \\
\hline & Upper & $(n, \%)$ & 33 & 4.38 \\
\hline \multirow[t]{4}{*}{ Attachment style } & Secure & $(n, \%)$ & 144 & 19.10 \\
\hline & Avoidant & $(n, \%)$ & 187 & 24.80 \\
\hline & Preoccupied & $(n, \%)$ & 145 & 19.23 \\
\hline & Fearful & $(n, \%)$ & 278 & 36.87 \\
\hline \multirow{2}{*}{ Pathological Internet use } & $\mathrm{CIAS} \geq 64$ & & & \\
\hline & WHODAS $2.0 \geq 17$ & $(n, \%)$ & 66 & 8.75 \\
\hline Pathological Internet use & $\mathrm{YIAT} \geq 40$ & $(n, \%)$ & 150 & 19.89 \\
\hline
\end{tabular}

Note. 754 college students, aged from 17 to 50 years, participated in the study. YIAT = Young Internet Addiction Test; CIAS = Chen Internet Addiction Scale; WHODAS 2.0 = WHO Disability Assessment Schedule 2.0 Short Form - Self-Assessment

participated in the study after their courses. Volunteers provided written informed consent and then completed a set of battery of questionnaires. Respondents were not compensated for their participation. The approval for the procedures of the study was granted by Van Yüzüncü Yıl University Institutional Ethical Board of Social and Human Units.

\section{Psychometric Instruments}

Chen Internet Addiction Scale (CIAS): The 26-item self-report questionnaire was designed to assess Internet addiction in general population (Chen et al., 2003). Respondents are asked to rate each question on a Likert type 4-point scale, ranging from 1 to 4 . The CIAS yields five sub-scales of Compulsive use, Withdrawal, Tolerance, Interpersonal and Health Problems and Time Management Difficulties. The initial validation study reported excellent internal reliability coefficients for the scale and subscales, ranging from 0.79 to 0.93 .

Young Internet Addiction Test (YIAT): The YIAT, a 20-item self-administered scale, was designed to assess problematic Internet use (K. Young, 1998; K. S. Young, 1998). Each item is rated on a Likert type scale, ranging from 0 to 5 . A total score is obtained by averaging the summed scores of the items. The Turkish version of the scale had a Cronbach's alpha of $a=0.93$ (Boysan et al., 2017).

\section{Experiences in Close Relationship-Revised} (ECR-R): The ECR-R is developed to screen aspects of adult attachment styles (Fraley, Waller, \& Brennan, 2000). The scale consists of 36 self-report questions, scored on a 7 -point scale. The instrument yields scores on two dimensions, each was comprised of 18 items, including attachment anxiety and attachment avoidance. The Turkish version of the scale revealed good internal consistency with a Cronbach's $a=0.90$ for attachment avoidance and $a=0.86$ for attachment anxiety (Selcuk, Gunaydin, Sumer, \& Uysal, 2005).

\section{Difficulties in Emotional Regulation Scale (DERS):} The DERS (Gratz \& Roemer, 2004) is a 36 item self-report instrument designed to assess difficulties in emotion regulation. Each item is rated on a 5-point scale, ranging from 1 to 5 . The instrument yields six sub-scales: nonacceptance of emotional responses, difficulties engaging in goal directed behaviour, impulse control difficulties, lack of emotional awareness, limited access to emotion regulation strategies, and lack of emotional clarity. Turkish version of the DERS had promising psychometric 
properties with a internal reliability coefficient of $a=0.94$ (Ruganci \& Gencoz, 2010).

\section{Center for Epidemiological Studies Depression} Scale (CES-D): The CES-D (Radloff, 1977) is a 20-item self-administered questionnaire developed to assess severity of depressive symptomatology. Items are rated on a 4-point Likert-type scale, ranging from 0 to 3 . Items $4,8,12$, and 16 are reversed scored. Scores on the 20 items are summed to yield a total depressive severity score. The Turkish version of the CES-D was shown to have high convergent validity and internal reliability (Lehmann et al., 2011).

Beck Anxiety Inventory (BAI): The BAI (Beck, Brown, Epstein, \& Steer, 1988) is a 21-item self-report questionnaire designed to assess presence and severity of physiological anxiety symptoms. Respondents are asked to rate each item on a 4-point scale, ranging from 0 (Not at all) to 3 (Severely). The Turkish version was demonstrated to have good psychometric properties (Ulusoy, Sahin, \& Erkmen, 1998).

\section{WHO Disability Assessment Schedule 2.0 - 12} Item Self-Report (WHODAS 2.0 - SR): WHODAS 2.0 was developed to assess activity limitations and participant restrictions in the prior month (Rehm et al., 1999). The scale assesses functional impairment in six life domains: 1) communication, 2) self-care, 3) mobility, 4) interpersonal relations, 5) work and household roles and 6) community roles. There are 36 and 12 item versions that we used 12-item self report version of the WHODAS 2.0. Given the population norms for item response theory based scoring of the WHODAS 2.0 short version (Üstün et al., 2010), a score of 17 corresponding to the $90^{\text {th }}$ percentile was utilized to demarcate pathological Internet use related disability in the current study.

\section{Data Analysis}

Initially, we begin with obtaining descriptive statistics for socio-demographic characteristics of the sample. Descriptive item statistics were computed for the psychometric instruments utilized in the current study.
Using confirmatory structural equation modeling, we tested whether original factor structure of the CIAS fit to the data collected in the present study. One-way analysis of variance analysis was run to explore differences in scale scores across attachment styles. To make comparisons between the overlapping features of the constructs measured by Chen Internet Addiction Scale and Young Internet Addiction Test, we adhered to signal detection analysis approach and detected an optimal cutoff value for the Young Internet Addiction Test. Lastly, we run two logistic regression models in which Internet addicts scored pathological levels on the Chen Internet Addiction Scale ( $\geq 64$ ) plus WHODAS 2.0 ( $\geq 17$ ) and on the Young Internet Addiction Test ( $\geq 40)$ were dependent variable in each logistic model. Difficulties in emotional regulation, functional impairment, depression, anxiety, attachment anxiety and avoidance were regressed on the dependent variable in each logistic regression analysis while adjusting for socio-demographic characteristics.

\section{RESULTS}

\section{Dimensionality and factorial validity of the Chen Internet Addiction Scale}

CFA was performed on the 26 items of the Turkish version of CIAS using maximum likelihood estimation method with robust standard errors on the overall sample $(\mathrm{N}=754)$ to evaluate two competing models (a general 1-factor model vs original 5-factor latent structure).

The results derived from the CFA when testing the one general factor solution showed poor overall fit: $S-B \chi^{2}$ $(299)=1161.121 p<0.001 ;$ RMSEA $=0.06 ;$ SRMR $=0.05$; $C F I=0.85$. On the other hand, the results of the CFA performed on the initial validation study 5 -factor latent structure yielded acceptable model fit according to the guideline proposed by $\mathrm{Hu}$ and Bentler (1999): S-B $\chi^{2}$ $(289)=883.464 p<0.001 ; \operatorname{RMSEA}=0.05 ; \mathrm{SRMR}=0.05$; $\mathrm{CFI}=0.90$.

\section{Descriptive statistics for the psychometric measures}

Means, standard deviations and item statistics for the psychometric instruments are presented in Table 2. The 


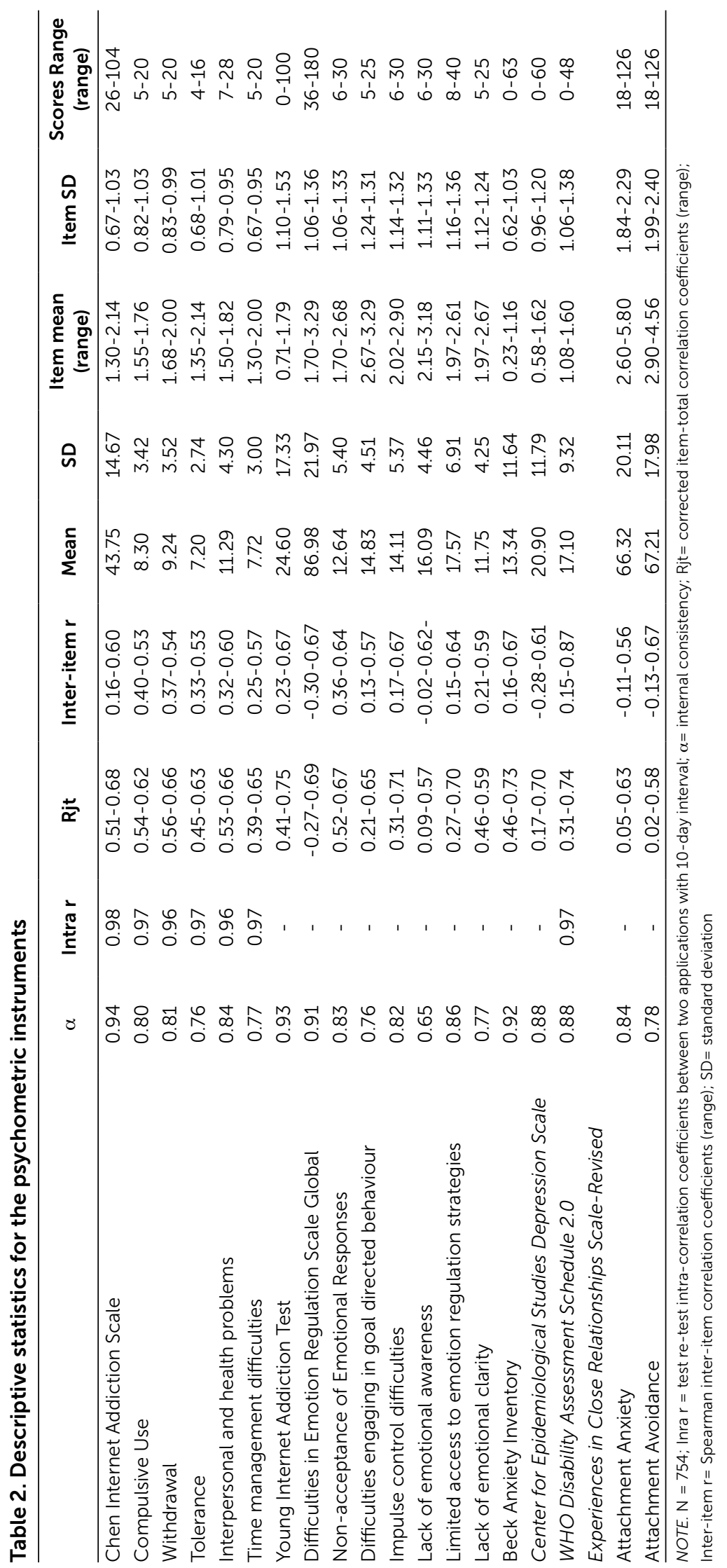


Table 3. Pearson product-moment correlation coefficients between the CIAS and YAIT scores

\begin{tabular}{|c|c|c|c|c|c|c|c|}
\hline & 1 & 2 & 3 & 4 & 5 & 6 & 7 \\
\hline 1. Chen Internet Addiction Scale & 1.00 & $0.89 * *$ & 0.84 ** & $0.86 * *$ & $0.89 * *$ & $0.84 * *$ & $0.85 * *$ \\
\hline 2. Compulsive Use & & 1.00 & 0.71 ** & $0.72 * *$ & 0.72 ** & $0.67 * *$ & 0.76 ** \\
\hline 3. Withdrawal & & & 1.00 & $0.69 * *$ & $0.61 * *$ & $0.60 * *$ & $0.68 * *$ \\
\hline 4. Tolerance & & & & 1.00 & $0.70 * *$ & $0.67 * *$ & $0.74 * *$ \\
\hline 5. Interpersonal and health problems & & & & & 1.00 & 0.72 ** & $0.76 * *$ \\
\hline 6. Time management difficulties & & & & & & 1.00 & $0.75 * *$ \\
\hline 7. Young Internet Addiction Test & & & & & & & 1.00 \\
\hline
\end{tabular}

NOTE: **:p<0.01; CIAS= Chen Internet Addiction Test; YIAT=Young Internet Addiction Test

total and five subscales of the Turkish form of the CIAS revealed excellent internal reliability, with Cronbach's alphas ranging from 0.76 to 0.94 . The same was true for the temporal stability of the scale, with re-test intracorrelations ranging from 0.96 to 0.98 . The item discrimination indexes in terms of corrected item-total correlation coefficients were greater than $\geq 0.50$ indicative of excellent item reliability and validity. Overall, the Turkish version of the CIAS showed sound and promising psychometric features.

\section{Pearson correlations}

We run Pearson product-moment correlation coefficient to evaluate the shared variance between total and sub-scales scores of the CIAS and YIAT. The correlation analyses showed that YIAT total scores strongly correlated with total and sub-scales scores of the CIAS, ranging from 0.68 to 0.85 . Findings are presented in Table 3.

\section{Signal detection analysis}

We used the cut values of the CIAS ( $\geq 64$ ) plus the WHODAS 2.0 ( $\geq 17$ ) as the gold standard for a principal diagnosis of Internet addiction. We detected 66 individuals were Internet addicts. The first receiver operating characteristic analysis assessed the ability of the CIAS total score per se to precisely identify 66 individuals with Internet addiction from a sample of 754 college students. The area under the curve (AUC) was very close to 1.00 ( $A \cup C=0.985, p<0.001$, Asymptotic 95\% Confidence Interval $=0.978-0.993)$, which is indicative of excellent diagnostic efficiency of the cut-off value (See Figure 1). The cut score simultaneously optimizing both sensitivity and specificity was derived for CIAS total scores. Not surprisingly, as can be seen in Table 6, the cut score on the CIAS $\geq 64$ simultaneously optimized both sensitivity (100\%) and specificity (96.8\%), with an excellent diagnostic accuracy (97.1\%). This result can be interpreted in a way that the initial proposed cut-off for the CIAS total score by Ko et al. (2005; 2005; 2009), well captures functional impairment related to pathological Internet use and can be reliably used in screening community samples.

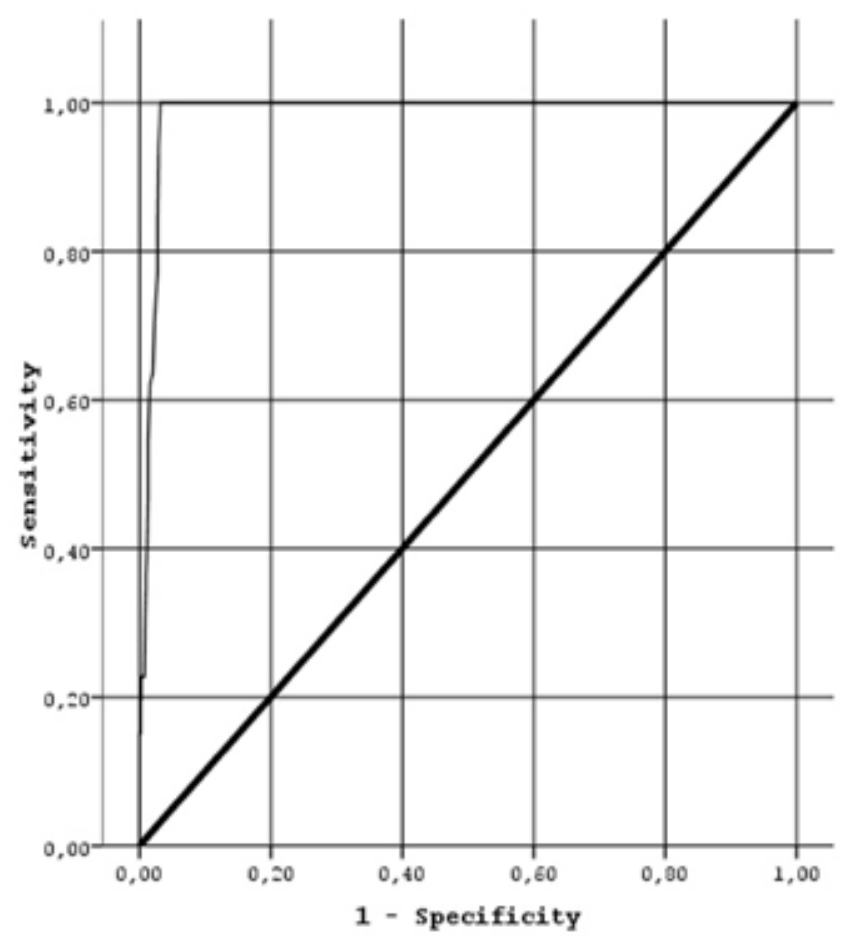

Figure 1. Receiver operating characteristic analysis curve for the CIAS total score in a sample of college students. The break point of the line closest to the left upper corner denotes the point that simultaneously optimizes specificity and sensitivity of the CIAS. 
The second receiver operating characteristic analysis assessed the ability of YIAT total score to correctly identify 66 individuals with Internet addiction from the same sample. The analysis revealed a strong signal

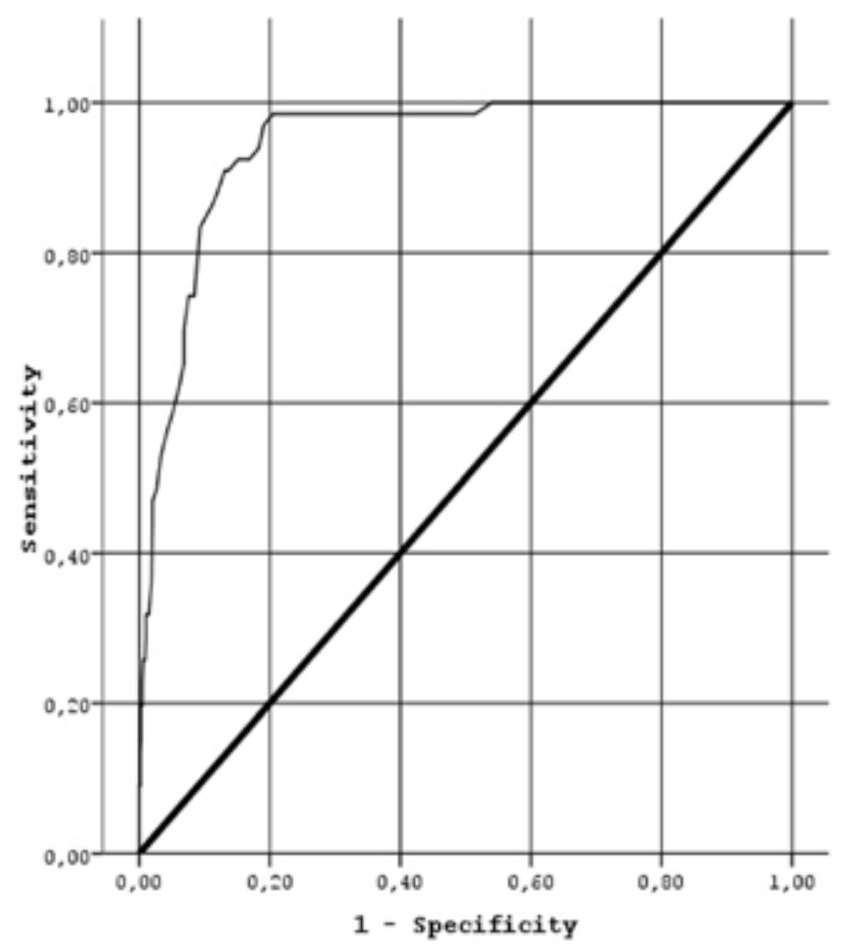

Figure 2. Receiver operating characteristic analysis curve for the YIAT total score in a sample of college students. The break point of the line closest to the left upper corner denotes the point that simultaneously optimizes specificity and sensitivity of the YIAT. detecting curve for the YIAT total score (AUC=0.943, $p<$ 0.001, Asymptotic 95\% Confidence Interval $=0.922$ 0.965). (See Figure 2). The cut score optimizing both sensitivity and specificity were derived for values of the YIAT total score. When sensitivity and specificity were both optimized (cut score $=40$ ), 60 of 66 Internet addicts (90.90\%) and 598 of 688 non-addicts (86.9\%) were correctly detected. Overall, $87.3 \%$ of the sample was correctly classified using cut score of the YIAT total score. Sensitivity, specificity and optimal cut values for the CAIS and the YIAT are presented in Table 4.

\section{ANOVAs across attachment styles}

We performed nineteen one-way analysis of variance models to investigate the mean differences in scores on Internet addiction as measured by the CIAS and YIAT, emotional dysregulation as indexed by the subscales of the DERS, anxiety and depression as rated on the BAI and CES-D and functional impairment as measured by the WHODAS 2.0 self-report across attachment styles. All ANOVA models indicated significant $F$ values that posthoc analyses were performed using Bonferroni multiple comparison test.

ANOVA models comparing subscales of the CIAS and IAT total scores across attachment styles showed that people with preoccupied and fearful attach styles were at greater risk for Internet addiction relative to secure and

Table 4. Sensitivity and specificity for the CIAS and YIAT total scores according to the gold standard based on the CIAS $(\geq 64)$ plus WHODAS $2.0(\geq 17)$ cutoffs

\begin{tabular}{|c|c|c|c|c|c|}
\hline CIAS total & Sensitivity & Specificity & YIAT Total & Sensitivity & Specificity \\
\hline 57.50 & 1.000 & 0.911 & 33.50 & 0.985 & 0.795 \\
\hline 58.50 & 1.000 & 0.924 & 34.50 & 0.970 & 0.810 \\
\hline 59.50 & 1.000 & 0.932 & 35.50 & 0.939 & 0.817 \\
\hline 60.50 & 1.000 & 0.940 & 36.50 & 0.924 & 0.831 \\
\hline 61.50 & 1.000 & 0.946 & 37.50 & 0.924 & 0.849 \\
\hline 62.50 & 1.000 & 0.959 & 38.50 & 0.909 & 0.863 \\
\hline$\neq 63.50$ & 1.000 & 0.968 & $\$ 39.50$ & 0.909 & 0.869 \\
\hline 64.50 & 0.939 & 0.971 & 40.50 & 0.879 & 0.881 \\
\hline 65.50 & 0.833 & 0.972 & 41.50 & 0.864 & 0.888 \\
\hline 66.50 & 0.773 & 0.972 & 42.50 & 0.833 & 0.907 \\
\hline 67.50 & 0.712 & 0.977 & 43.50 & 0.742 & 0.916 \\
\hline 68.50 & 0.636 & 0.980 & 44.50 & 0.742 & 0.920 \\
\hline 69.50 & 0.621 & 0.984 & 45.50 & 0.742 & 0.924 \\
\hline
\end{tabular}

Note. "indicated optimal cutoff values for the CIAS and YIAT total scores. CIAS= Chen Internet Addiction Test; YIAT=Young Internet Addiction Test; WHODAS 2.0 = WHO Disability Assessment Schedule 2.0 Short Form - Self Assessment 


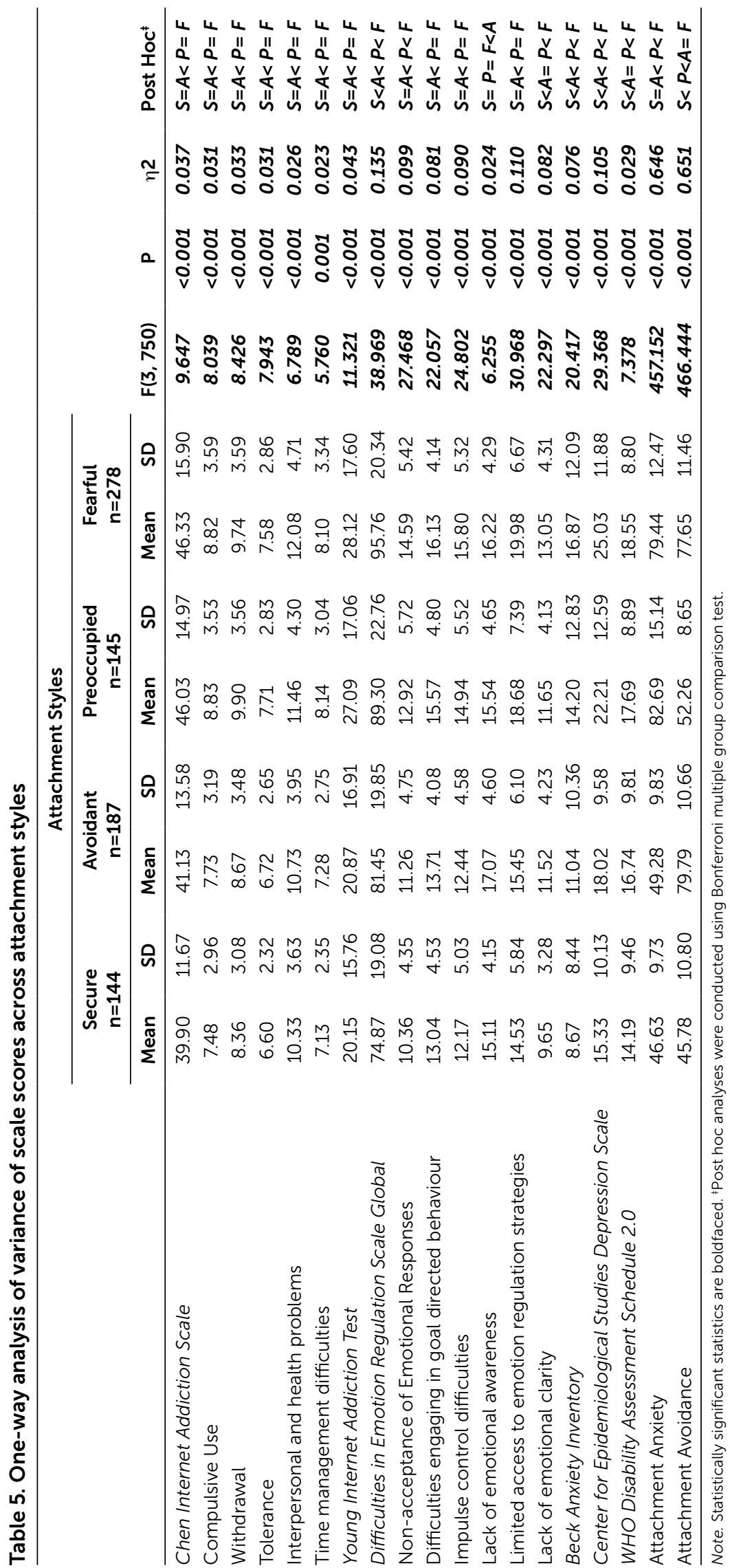


Table 6. Logistic regression analyses on pathological Internet use

\begin{tabular}{lcccccc}
\hline & \multicolumn{2}{c}{ CIAS $\geq \mathbf{6 4}$ plus WHODAS.20 $\geq \mathbf{1 7}$} & \multicolumn{3}{c}{ YIAT $\geq \mathbf{4 0}$} \\
\cline { 2 - 6 } & $\mathbf{P}$ & Odds Ratio & $\mathbf{9 5 \%} \mathbf{C l}$ & $\mathbf{P}$ & Odds Ratio & $\mathbf{9 5 \%}$ CI \\
\hline Age & 0.971 & 0.998 & $0.909-1.097$ & $\mathbf{0 . 0 2 7}$ & $\mathbf{0 . 9 1 6}$ & $\mathbf{0 . 8 4 8 - 0 . 9 9 0}$ \\
Gender & $<\mathbf{0 . 0 0 1}$ & $\mathbf{0 . 1 7 5}$ & $\mathbf{0 . 0 8 8 - 0 . 3 4 5}$ & $<\mathbf{0 . 0 0 1}$ & $\mathbf{0 . 3 6 1}$ & $\mathbf{0 . 2 3 3 - 0 . 5 6 0}$ \\
Income & 0.092 & 1.853 & $0.904-3.799$ & 0.550 & 1.157 & $0.716-1.870$ \\
Non-acceptance of Emotional Responses & 0.123 & 0.952 & $0.893-1.014$ & 0.706 & 1.009 & $0.965-1.054$ \\
Difficulties engaging in goal directed behaviour & 0.135 & 1.072 & $0.978-1.175$ & $\mathbf{0 . 0 3 1}$ & $\mathbf{1 . 0 6 8}$ & $\mathbf{1 . 0 0 6 - 1 . 1 3 3}$ \\
Impulse control difficulties & 0.726 & 0.986 & $0.910-1.068$ & 0.361 & 0.975 & $0.923-1.030$ \\
Lack of emotional awareness & 0.964 & 0.998 & $0.924-1.079$ & 0.597 & 0.986 & $0.936-1.038$ \\
Limited access to emotion regulation strategies & 0.725 & 1.013 & $0.945-1.085$ & 0.971 & 0.999 & $0.953-1.047$ \\
Lack of emotional clarity & $<\mathbf{0 . 0 0 1}$ & $\mathbf{1 . 2 2 8}$ & $\mathbf{1 . 1 1 8 - 1 . 3 4 9}$ & $<\mathbf{0 . 0 0 1}$ & $\mathbf{1 . 1 5 4}$ & $\mathbf{1 . 0 8 4 - 1 . 2 2 8}$ \\
Beck Anxiety Inventory & $\mathbf{0 . 0 1 7}$ & $\mathbf{1 . 0 3 4}$ & $\mathbf{1 . 0 0 6 - 1 . 0 6 2}$ & $\mathbf{0 . 0 0 1}$ & $\mathbf{1 . 0 3 4}$ & $\mathbf{1 . 0 1 4 - 1 . 0 5 4}$ \\
Center for Epidemiological Studies Depression Scale & $\mathbf{0 . 0 0 4}$ & $\mathbf{1 . 0 5 3}$ & $\mathbf{1 . 0 1 7 - 1 . 0 9 1}$ & 0.059 & 1.023 & $0.999-1.048$ \\
Attachment Anxiety & 0.216 & 1.010 & $0.994-1.027$ & 0.787 & 1.002 & $0.990-1.013$ \\
Attachment Avoidance & 0.384 & 1.009 & $0.989-1.028$ & 0.446 & 1.005 & $0.992-1.017$ \\
\hline
\end{tabular}

Note. Statistically significant statistics are boldfaced. Gender: 0=Male; 1=Female; Income: $0=$ Low, $1=$ Average, $2=U$ uper.

$\mathrm{CIAS}=$ Chen Internet Addiction Test; YIAT=Internet Addiction Test

avoidant individuals. In comparison to preoccupied and fearful attachment, secure individuals in general reported better emotional regulation capacity as well as avoidant type. Fearful respondents were at greater risk for development of depression and anxiety, following by preoccupied individuals. The same was true for functional impairment as measured by the WHODAS 2.0 scores. Findings are presented in Table 5.

\section{Logistic regression analysis}

To explore the risk factors for pathological Internet use, we run two logistic regression analyses in which individuals who reported 64 or higher scores on the CIAS plus 17 or higher on the WHODAS 2.0 and individuals who scored 40 or higher on the YIAT were binary dependent variables. In the regression models, sociodemographic variables in terms of age, gender and income, six sub-scales of the DERS, two dimensions of the $E C R-R$, depression as indexed by the CES-D and anxiety as measured by the BAI were sequentially regressed on dependent variables.

In the first regression analysis, we found that being male $(\mathrm{OR}=0.175, p<0.00195 \% \mathrm{Cl}=0.088-0.345)$, lack of emotional clarity $(\mathrm{OR}=1.228, p<0.00195 \% \mathrm{Cl}=1.118$ 1.349), anxiety $(\mathrm{OR}=1.034, p=0.01795 \% \mathrm{Cl}=1.006$ 1.062), and depression $(\mathrm{OR}=1.053, p=0.00495 \% \mathrm{Cl}=$
1.017-1.091) significantly contributed to the unique variance of pathological Internet use.

In the second regression model in which YIAT cut value was utilized to identify Internet addicts, we found that younger age $(\mathrm{OR}=0.916, p=0.02795 \% \mathrm{Cl}=0.848$ $0.990)$, being male $(\mathrm{OR}=0.361, p<0.00195 \% \mathrm{Cl}=0.233$ $0.560)$, Difficulties engaging in goal directed behaviour $(\mathrm{OR}=1.068, p=0.03195 \% \mathrm{Cl}=1.006-1.133)$, lack of emotional clarity $(O R=1.154, p<0.00195 \% \mathrm{Cl}=1.084$ $1.228)$, and anxiety $(\mathrm{OR}=1.034, p=0.00195 \% \mathrm{Cl}=$ 1.014-1.054) were significant predictors of pathological Internet use. Results are presented in Table 6.

\section{DISCUSSION}

Expanding on the Ko et al.'s work (2005; 2005; 2009), we tested the diagnostic efficiency of the cutoff on the CIAS ( $\geq 64$ ) through using an assessment procedure involving the WHODAS 2.0 to determine functional impairment in regard to unduly Internet use along with the CIAS total scores. We also determined the optimal demarcation point on the YIAT scores for the Internet use disorders relying on the cutoff on the CIAS ( $\geq 64)$ plus WHODAS $2.0(\geq 17)$. Based on the data recruited from a relatively large sample of college students we detected 66 individuals were Internet addicts (8.75\%). The 
prevalence rate observed in the current sample was consistent with the previous reports (D. Gentile, 2009; Grusser, Thalemann, \& Griffiths, 2007; Salguero \& Moran, 2002), indicating that online addiction is not rare in normal community population. Signal detection analysis attested to the optimal cutoff point originally proposed by Ko et al. $(2005 ; 2005 ; 2009)$ for the Turkish version of the CIAS and indicated excellent diagnostic efficiency that $97.1 \%$ of participants were correctly classified predicated on their online addiction status. Moreover, a cutoff point of 40 or higher than 40 on the YIAT was observed as optimal detection point correctly differentiate participants with pathological online addictive behaviours from healthy participants. Using the cutoff point of the YIAT $\geq 40,87.3 \%$ of the respondents were correctly classified. Our results confirmed and expanded the previous findings in the literature (Aboujaoude, 2010; Ko, Yen, Yen, et al., 2005; Ko, Yen, Chen, et al., 2005; Ko, Yen, Chen, Yang, et al., 2009; Kuss et al., 2014).

The emerging evidence relevant to the process of problematic Internet use suggests that such behaviours could be best understood on along a continuum ranging from normal use to pathological levels certain with severe impairment in functionality which can be conceptualized as a maladaptive self-regulatory strategy (Billieux \& Van der Linden, 2012; LaRose, Lin, \& Eastin, 2003; Spada, Langston, Nikcevic, \& Moneta, 2008; Tokunaga, 2015; Yu, Kim, \& Hay, 2013). High comorbid psychiatric conditions are typical in Internet use disorders rather than exception (Cho et al., 2013; Gamez-Guadix, 2014; D. A. Gentile et al., 2011; Ko et al., 2014; Ko, Yen, Chen, Yeh, et al., 2009) in which co-occurrence of online addictive behaviours and psychological problems seems to reciprocally related to each other (Anderson et al., 2017; Ciarrochi et al., 2016; G. Dong et al., 2011; Gamez-Guadix et al., 2013; van den Eijnden et al., 2008) that can be interpreted in a way emotion dysregulation interplays between internalizing and aberrant online behaviors to be regarded as externalizing behaviours. Even though this high comorbidity calls the concept of Internet addiction into question whether it is really a clinical entity or a behavioral problem secondary to other clinical conditions
On the other hand, emerging evidence indicates that difficulties in emotion regulation causally involves in development and maintenance of online behavioral problems (Billieux \& Van der Linden, 2012; Oktan, 2011; Yen et al., 2018; Yildiz, 2017). Several lines of research has consistently attested to the critical role of emotion regulation capacity on difficulties managing online behaviors underpinned by various vulnerability factors such as personality, perceived parental behaviors, metacognitions and distress tolerance (Akbari, 2017; Montag et al., 2016; Spada \& Marino, 2017; Yu et al., 2013). Our results were in consonant with the accumulated evidence that emotion regulation incapacity in terms of Difficulties engaging in goal directed behaviour and Lack of emotional clarity were significant antecedents of Internet addiction. Moreover, participants high in depressive and anxious symptomatology were at greater risk for overengagement in online addictive behaviours.

Interpersonal nature of emotion regulation and significant relations to early childhood experiences lying under the development of attachment capacity have long been recognized and well-documented (Cozolino, 2013; Schore, 2016; Siegel, 2012). In keeping with the view of interpersonal regulation of emotions, attachment insecurities were found to be tied to the excessive online behavioral engagement (M. P. Lin et al., 2011; Monacis et al., 2017a, 2017b; Schimmenti et al., 2012; Severino \& Craparo, 2013) putatively mediate by affective symptomatology (Shin et al., 2011) and highly associated with negative experiences in family environment (Kim \& Kim, 2015; Lei \& Wu, 2007), particularly adverse childhood experiences (Schimmenti et al., 2014). Our results were partially in line with attachment studies of online behavioral addiction that participants with preoccupied and fearful attachment style were more likely to exhibit undue engagement in online use resulting in functional impairment. Although these findings overlapped in part with the previous studies (Odaci \& Cikrikci, 2014; Savci \& Aysan, 2016), our data pointed out that a tendency to interpersonal avoidance seems to protect against Internet use disorders. Given the research findings concerned with the relations between attachment insecurities and social network use (Jenkins-Guarnieri et 
al., 2012; Lee, 2013), avoidant people may less likely use maladaptive online regulation strategies. On the other hand, the associations of attachment avoidance and anxiety with excessive Internet use were no longer significant once their shared variance with emotional dysregulation, affective symptoms and demographic variables.

Several important limitations of this study should be highlighted. First, our data sampled only college students and participants were not randomly selected that the study group is not representative of young adults. Also cohort studies with different age groups should be conducted to firmly confirm our results. Second, the research design of the study was cross sectional. Longitudinal design studies are needed to obtain more reliable relations including precise causality between the variables of interest. Third, from the view of social cognitive models of media use, due to the widespread use of online media it is difficult to distinguish between pathological and unduly use of Internet and long times spent online may not always necessarily be the case pathological (LaRose, 2010; LaRose \& Eastin, 2004; LaRose et al., 2003; Tokunaga, 2017; Tokunaga \& Rains, 2010). Finally, pathological Internet use has been found to be related to a number of factors such as identity status (Morsunbul, 2014), family factors (Ko et al., 2015; Park, Kim, \& Cho, 2008; Yen, Yen, Chen, Chen, \& Ko, 2007), social support (Durkee et al., 2012). Moreover, the robust relations between physical activity and emotional wellbeing have been documented (Irandoust \& Taheri, 2017; Taheri \& Irandoust, 2018) that sedentary behaviours seem to be an integral part of maladaptive unduly Internet use (Vandelanotte, Sugiyama, Gardiner, \& Owen, 2009). Therefore, comprehensive investigations capturing the lifestyle of Internet addicts will provide more fruitful

\section{References}

Aboujaoude, E. (2010). Problematic Internet use: an overview. World Psychiatry, 9(2), 85-90.

Akbari, M. (2017). Metacognitions or distress intolerance: The mediating role in the relationship between emotional dysregulation and problematic internet use. Addictive Behaviors Reports, 6, 128-133. doi:10.1016/j.abrep.2017.10.004 information about the etiology of the disorder.

The term 'Internet addiction' still sparks hot debates about whether it is a clinical entity, a behavioral problem secondary to other disorders or a subtype of a supreme disorder which may be better understood in the scope of an umbrella conceptualization of a 'general behavioral addiction' factor (Shaffer, Hall, \& Vander Bilt, 2000; Starcevic, 2010, 2013). The confirmation of the cutpoint of the CIAS by means of adding the WHODAS 2.0 to assessment procedure to more profoundly assess the functional impairment with respect to pathological Internet use supported the notion that unduly online behaviours convey pathological aspects and can be clinically discriminated by using the proposed procedure utilized in the current study. Besides, the proposed assessment procedure could also be beneficial to determine prevalence rates and risky populations as to online addiction disorders in community dwelling and clinical samples, to more profoundly understand the underpinning mechanisms of the disorder and to evaluate the course and prognosis of online behavioral addictions. This study also add to our understanding that attachment insecurities and difficulties in emotion regulation as well as internalizing symptoms in terms of anxiety and depression which are robust correlates of attachment and emotion regulation seems to causally involve in development and perseverance of online addiction disorders.

Conflict of interest: The authors report no financial or other relationship relevant to the subject of this article.

Funding: The current study was not financially supported by any institution or organization.

Author Statement: The paper used the data set from the first author's master dissertation, expertly advised by the second author.

Al-Gamal, E., Alzayyat, A., \& Ahmad, M. M. (2016). Prevalence of Internet addiction and its association with psychological distress and coping strategies among university students in Jordan. Perspectives in Psychiatric Care, 52(1), 49-61. doi:10.1111/ppc.12102 
Aldao, A., Nolen-Hoeksema, S., \& Schweizer, S. (2010). Emotionregulation strategies across psychopathology: A meta-analytic review. Clinical Psychology Review, 30(2), 217-237. doi:10.1016/j.cpr.2009.11.004

American Psychiatric Association. (2013). Diagnostic and Statistical Manual of Mental Disorders, 5th Edition (DSM-5). Washington, DC: American Psychiatric Publishing.

Anderson, E. L., Steen, E., \& Stavropoulos, V. (2017). Internet use and Problematic Internet use: A systematic review of longitudinal research trends in adolescence and emergent adulthood. International Journal of Adolescence and Youth, 22(4), 430-454. doi:10.1080/02673843.2016.1227716

Bartholomew, K., \& Horowitz, L. M. (1991). Attachment styles among young adults: A test of a four category model. Journal of Personality and Social Psychology, 61, 226-244.

Beck, A. T., Brown, G., Epstein, N., \& Steer, R. A. (1988). An inventory for measuring clinical anxiety: Psychometric properties. Journal of Consulting and Clinical Psychology, 56(6), 893-897. doi:Doi 10.1037/0022-006x.56.6.893

Benaiges, I., Prat, G., \& Adan, A. (2010). Neuropsychological aspects of dual diagnosis. Current Drug Abuse Review, 3, 175-188.

Billieux, J., \& Van der Linden, M. (2012). Problematic use of the Internet and self-regulation: A review of the initial studies. The Open Addiction Journal, 5 (Suppl 1), 24-29.

Blackwell, D., Leaman, C., Tramposch, R., Osborne, C., \& Liss, M. (2017). Extraversion, neuroticism, attachment style and fear of missing out as predictors of social media use and addiction. Personality and Individual Differences, 116, 69-72. doi:10.1016/j.paid.2017.04.039

Bowlby, J. (1988). A secure base: Parent-child attachment and healthy human development. New York, NY: Basic Books.

Boysan, M., \& Çam, Z. (2016). An investigation into the role of attachment insecurities in obsessive-compulsive symptoms. British Journal of Guidance \& Counselling, 1-16. doi:10.1080/0 3069885.2016.1262533

Boysan, M., Kuss, D. J., Barut, Y., Aykose, N., Gulec, M., \& Ozdemir, O. (2017). Psychometric properties of the Turkish version of the Internet Addiction Test (IAT). Addictive Behaviors, 64, 247-252. doi:10.1016/j.addbeh.2015.09.002

Brand, M., Laier, C., \& Young, K. S. (2014). Internet addiction: coping styles, expectancies, and treatment implications. Frontiers in Psychology, 5. doi:10.3389/fpsyg.2014.01256

Brand, M., Young, K. S., \& Laier, C. (2014). Prefrontal control and Internet addiction: a theoretical model and review of neuropsychological and neuroimaging findings. Frontiers in Human Neuroscience, 8. doi:10.3389/fnhum.2014.00375

Brand, M., Young, K. S., Laier, C., Wolfling, K., \& Potenza, M. N. (2016). Integrating psychological and neurobiological considerations regarding the development and maintenance of specific Internet-use disorders: An Interaction of PersonAffect-Cognition-Execution (I-PACE) model. Neuroscience and Biobehavioral Reviews, 71, 252-266. doi:10.1016/j. neubiorev.2016.08.033

Brennan, K. A., Clark, C. L., \& Shaver, P. R. (1998). Self-report measurement of adult attachment: An integrative overview. In J. A. Simpson \& W. S. Rholes (Eds.), Attachment theory and close relationships (pp. 46-76). New York, NY: Guilford Press.

Cash, H., Rae, C. D., Steel, A. H., \& Winkler, A. (2012). Internet addiction: A brief summary of research and practice. Current Psychiatry Reviews, 8(4), 292-298. doi:10.2174/157340012803520513

Chen, S.-H., Weng, L.-J., Su, Y.-J., Wu, H.-M., \& Yang, P.-F. (2003). Development of a Chinese Internet Addiction Scale and its psychometric study. Chinese Journal of Psychology, 45(3), 279-294.
Cheng, C., Sun, P. Z., \& Mak, K. K. (2015). Internet addiction and psychosocial maladjustment: Avoidant coping and coping inflexibility as psychological mechanisms. Cyberpsychology Behavior and Social Networking, 18(9), 539-546. doi:10.1089/ cyber.2015.0121

Cho, S. M., Sung, M. J., Shin, K. M., Lim, K. Y., \& Shin, Y. M. (2013). Does psychopathology in childhood predict Internet addiction in male adolescents? Child Psychiatry and Human Development, 44(4), 549-555. doi:10.1007/s10578-012-0348-4

Chou, W. P., Ko, C. H., Kaufman, E. A., Crowell, S. E., Hsiao, R. C., Wang, P. W., .. Yen, C. F. (2015). Association of stress coping strategies with Internet addiction in college students: The moderating effect of depression. Comprehensive Psychiatry, 62, 27-33. doi:10.1016/j.comppsych.2015.06.004

Ciarrochi, J., Parker, P., Sahdra, B., Marshall, S., Jackson, C., Gloster, A. T., \& Heaven, P. (2016). The development of compulsive Internet use and mental health: A four-year study of adolescence. Developmental Psychology, 52(2), 272-283. doi:10.1037/dev0000070

Cozolino, L. (2013). The neuroscience of human relationships: Attachment and the developing social brain (Second edition ed.). New York, NY: W. W. Norton \& Company.

Dong, G., Lu, Q., Zhou, H., \& Zhao, X. (2011). Precursor or sequela: Pathological disorders in people with Internet addiction disorder. PLoS One, 6(2), e14703. doi:10.1371/journal. pone.0014703

Dong, G. H., \& Potenza, M. N. (2014). A cognitive-behavioral model of Internet gaming disorder: Theoretical underpinnings and clinical implications. Journal of Psychiatric Research, 58, 7-11. doi:10.1016/j.jpsychires.2014.07.005

Durkee, T., Kaess, M., Carli, V., Parzer, P., Wasserman, C., Floderus, B., ... Wasserman, D. (2012). Prevalence of pathological internet use among adolescents in Europe: demographic and social factors. Addiction, 107(12), 2210-2222. doi:10.1111/j.1360-0443.2012.03946.x

Flores, P. J. (2004). Addiction as an attachment disorder. Lanham: Jason Aronson.

Fraley, R. C., Waller, N. G., \& Brennan, K. A. (2000). An item response theory analysis of self-report measures of adult attachment. Journal of Personality and Social Psychology, 78(2), 350-365. doi:Doi 10.1037/0022-3514.78.2.350

Gamez-Guadix, M. (2014). Depressive symptoms and problematic Internet use among adolescents: Analysis of the longitudinal relationships from the cognitive-behavioral model. Cyberpsychology Behavior and Social Networking, 17(11), 714719. doi:10.1089/cyber.2014.0226

Gamez-Guadix, M., Orue, I., Smith, P. K., \& Calvete, E. (2013). Longitudinal and reciprocal relations of cyberbullying with depression, substance use, and problematic Internet use among adolescents. Journal of Adolescent Health, 53(4), 446452. doi:10.1016/j.jadohealth.2013.03.030

Gentile, D. (2009). Pathological video-game use among youth ages 8 to 18: A national study. Psychological Science, 20(5), 594-602. doi:10.1111/j.1467-9280.2009.02340.x

Gentile, D. A., Choo, H., Liau, A., Sim, T., Li, D. D., Fung, D., \& Khoo, A. (2011). Pathological video game use among youths: A twoyear longitudinal study. Pediatrics, 127(2), E319-E329. doi:10.1542/peds.2010-1353

Gratz, K. L., \& Roemer, L. (2004). Multidimensional assessment of emotion regulation and dysregulation: Development, factor structure, and initial validation of the difficulties in emotion regulation scale. Journal of Psychopathology and Behavioral Assessment, 26 (1), 41 - 54 . doi:10.1023/B:Joba.0000007455.08539.94 
Griffiths, M. (2005). A 'components' model of addiction within a biopsychosocial framework. Journal of Substance Use, 10(4), 191-197. doi:10.1080/14659890500114359

Griffiths, M. D., van Rooij, A. J., Kardefelt-Winther, D., Starcevic, V., Kiraly, O., Pallesen, S., . . Demetrovics, Z. (2016). Working towards an international consensus on criteria for assessing internet gaming disorder: a critical commentary on Petry et al. (2014). Addiction, 111(1), 167-175. doi:10.1111/add.13057

Grusser, S. M., Thalemann, R., \& Griffiths, M. D. (2007). Excessive computer game playing: Evidence for addiction and aggression? Cyberpsychology \& Behavior, 10(2), 290-292. doi:10.1089/cpb.2006.9956

Hormes, J. M., Kearns, B., \& Timko, C. A. (2014). Craving Facebook? Behavioral addiction to online social networking and its association with emotion regulation deficits. Addiction, 109(12), 2079-2088. doi:10.1111/add.12713

Hu, L. T., \& Bentler, P. M. (1999). Cutoff criteria for fit indexes in covariance structure analysis: Conventional criteria versus new alternatives. Structural Equation Modeling-a Multidisciplinary Journal, 6(1), 1-55. doi:10.1080/10705519909540118

Irandoust, K., \& Taheri, M. (2017). The effect of vitamin D supplement and indoor vs outdoor physical activity on depression of obese depressed women. Asian Journal of Sports Medicine, 8(3), e13311. doi:10.5812/asjsm.13311

Jenkins-Guarnieri, M. A., Wright, S. L., \& Hudiburgh, L. M. (2012). The relationships among attachment style, personality traits, interpersonal competency, and Facebook use. Journal of Applied Developmental Psychology, 33(6), 294-301. doi:10.1016/j.appdev.2012.08.001

Kardefelt-Winther, D. (2017). Conceptualizing Internet use disorders: Addiction or coping process? Psychiatry and Clinical Neurosciences, 71(7), 459-466. doi:10.1111/pcn.12413

Kim, K., \& Kim, K. (2015). Internet game addiction, parental attachment, and parenting of adolescents in South Korea. Journal of Child \& Adolescent Substance Abuse, 24(6), 366371. doi:10.1080/1067828x.2013.872063

Ko, C. H., Liu, T. L., Wang, P. W., Chen, C. S., Yen, C. F., \& Yen, J. Y. (2014). The exacerbation of depression, hostility, and social anxiety in the course of Internet addiction among adolescents: A prospective study. Comprehensive Psychiatry, 55, 1377-1384.

Ko, C. H., Wang, P. W., Liu, T. L., Yen, C. F., Chen, C. S., \& Yen, J. Y. (2015). Bidirectional associations between family factors and Internet addiction among adolescents in a prospective investigation. Psychiatry and Clinical Neurosciences, 69(4), 192-200. doi:10.1111/pcn.12204

Ko, C. H., Yen, C. F., Yen, C. N., Yen, J. Y., Chen, C. C., \& Chen, S. H. (2005). Screening for Internet addiction: an empirical study on cut-off points for the Chen Internet Addiction Scale. The Kaohsiung Journal of Medical Sciences, 21(12), 545-551. doi:10.1016/S1607-551X(09)70206-2

Ko, C. H., Yen, J. Y., Chen, C. C., Chen, S. H., \& Yen, C. F. (2005). Proposed diagnostic criteria of Internet addiction for adolescents. The Journal of nervous and mental disease, 193(11), 728-733. doi:10.1097/01.nmd.0000185891.13719.54

Ko, C. H., Yen, J. Y., Chen, C. S., Yeh, Y. C., \& Yen, C. F. (2009). Predictive values of psychiatric symptoms for Internet addiction in adolescents A 2-year prospective study. Archives of Pediatrics and Adolescent Medicine, 163(10), 937-943. doi:10.1001/archpediatrics.2009.159

Ko, C. H., Yen, J. Y., Chen, S. H., Yang, M. J., Lin, H. C., \& Yen, C. F. (2009). Proposed diagnostic criteria and the screening and diagnosing tool of Internet addiction in college students. Comprehensive Psychiatry, 50(4), 378-384. doi:10.1016/j. comppsych.2007.05.019
Kun, B., \& Demetrovics, Z. (2010). Emotional intelligence and addictions: A systematic review. Substance Use and Misuse, 45(7-8), 1131-1160. doi:10.3109/10826080903567855

Kuss, D. J. (2013). Internet gaming addiction: current perspectives. Psychology Research and Behavior Management, 6, 125-137. doi:10.2147/PRBM.S39476

Kuss, D. J., Griffiths, M. D., Karila, L., \& Billieux, J. (2014). Internet addiction: A systematic review of epidemiological research for the last decade. Current Pharmaceutical Design, 20(25), 40264052. doi:10.2174/13816128113199990617

Kuss, D. J., \& Lopez-Fernandez, O. (2016). Internet addiction and problematic Internet use: A systematic review of clinical research. World Journal of Psychiatry, 6(1), 143-176. doi:10.5498/wjp.v6.i1.143

LaRose, R. (2010). The problem of media habits. Communication Theory, 20(2), 194-+. doi:10.1111/j.1468-2885.2010.01360.x

LaRose, R., \& Eastin, M. S. (2004). A social cognitive theory of Internet uses and gratifications: Toward a new model of media attendance. Journal of Broadcasting \& Electronic Media, 48(3), 358-377. doi:10.1207/s15506878jobem4803_2

LaRose, R., Lin, C. A., \& Eastin, M. S. (2003). Unregulated Internet usage: Addiction, habit, or deficient self-regulation? Media Psychology, 5(3), 225-253. doi:Doi 10.1207/ S1532785xmep0503_01

Lee, D. Y. (2013). The role of attachment style in building social capital from a social networking site: The interplay of anxiety and avoidance. Computers in Human Behavior, 29(4), 14991509. doi:10.1016/j.chb.2013.01.012

Lehmann, V., Makine, C., Karsidag, C., Kadioglu, P., Karsidag, K., \& Pouwer, F. (2011). Validation of the Turkish version of the Centre for Epidemiologic Studies Depression Scale (CES-D) in patients with type 2 diabetes mellitus. Bmc Medical Research Methodology, 11. doi:10.1186/1471-2288-11-109

Lei, L., \& Wu, Y. (2007). Adolescents' paternal attachment and Internet use. Cyberpsychology \& Behavior, 10(5), 633-639. doi:https://doi.org/10.1089/cpb.2007.9976

Li, D. P., Zhang, W. H., Li, X., Zhou, Y. Y., Zhao, L. Y., \& Wang, Y. H. (2016). Stressful life events and adolescent Internet addiction: The mediating role of psychological needs satisfaction and the moderating role of coping style. Computers in Human Behavior, 63, 408-415. doi:10.1016/j.chb.2016.05.070

Lin, J. H. (2015). The role of attachment style in Facebook use and social capital: Evidence from university students and a national sample. Cyberpsychology, Behavior, and Social Networking, 18(3), 173-180. doi:10.1089/cyber.2014.0341

Lin, J. H. (2016). Need for relatedness: A self-determination approach to examining attachment styles, Facebook use, and psychological well-being. Asian Journal of Communication, 26(2), 153-173. doi:10.1080/01292986.2015.1126749

Lin, M. P., Ko, H. C., \& Wu, J. Y. W. (2011). Prevalence and psychosocial risk factors associated with internet addiction in a nationally representative sample of college students in Taiwan Cyberpsychology, Behavior, and Social Networking, 14(12), 741-746. doi:10.1089/cyber.2010.0574

Linehan, M. M. (2014). DBT® skills training manual (Second Edition ed.). New York, NY: Guilford.

Liu, H. H., Shi, J. Q., Liu, Y. H., \& Sheng, Z. T. (2013). The moderating role of attachment anxiety on social network site use intensity and social capital. Psychological Reports, 112(1), 252-265. doi:10.2466/21.02.17.Pr0.112.1.252-265

Lopez-Fernandez, O. (2015). How has Internet addiction research evolved since the advent of Internet Gaming Disorder? An overview of cyberaddictions from a psychological perspective. Current Addiction Reports, 2(3), 263-271. doi:10.1007/s40429-015-0067-6 
Monacis, L., de Palo, V., Griffiths, M. D., \& Sinatra, M. (2017a). Exploring individual differences in online addictions: the role of identity and attachment. International Journal of Mental Health and Addiction, 15(4), 853-868. doi:10.1007/s11469-017-9768-5

Monacis, L., De Palo, V., Griffiths, M. D., \& Sinatra, M. (2017b). Social networking addiction, attachment style, and validation of the Italian version of the Bergen Social Media Addiction Scale. Journal of Behavioral Addictions, 6(2), 178-186. doi:10.1556/2006.6.2017.023

Montag, C., Sindermann, C., Becker, B., \& Panksepp, J. (2016). An affective neuroscience framework for the molecular study of Internet addiction. Frontiers in Psychology, 7. doi: 10.3389/ fpsyq.2016.01906

Morsunbul, U. (2014). Internet addiction in adolescence period: its relations with identity style and ruminative exploration. Anadolu Psikiyatri Dergisi-Anatolian Journal of Psychiatry, 15(1), 77-83. doi:10.5455/apd.43504

Odaci, H., \& Cikrikci, O. (2014). Problematic internet use in terms of gender, attachment styles and subjective well-being in university students. Computers in Human Behavior, 32, 61-66. doi:10.1016/j.chb.2013.11.019

Oktan, V. (2011). The predictive relationship between emotion management skills and Internet addiction. Social Behavior and Personality, 39(10), 1425-1430. doi:10.2224/ sbp.2011.39.10.1425

Oldmeadow, J. A., Quinn, S., \& Kowert, R. (2013). Attachment style, social skills, and Facebook use amongst adults. Computers in Human Behavior, 29(3), 1142-1149. doi:10.1016/j. chb.2012.10.006

Park, S. K., Kim, J. Y., \& Cho, C. B. (2008). Prevalence of Internet addiction and correlations with family factors among South Korean adolescents. Adolescence, 43(172), 895-909.

Pontes, H. M., Kuss, D. J., \& Griffiths, M. D. (2015). Clinical psychology of Internet addiction: a review of its conceptualization, prevalence, neuronal processes, and implications for treatment. Neuroscience \& Neuroeconomics, 4, 11-23. doi:http://dx.doi.org/10.2147/NAN.S60982

Radloff, L. S. (1977). The CES-D Scale: A self-report depression scale for research in the general population. Applied Psychological Measurement, 1(3), 385-401.

Rehm, J., Üstün, T. B., Saxena, S., Nelson, C. B., Chatterji, S., Ivis, F., \& Adlaf, E. D. (1999). On the development and psychometric testing of the $\mathrm{WHO}$ screening instrument to assess disablement in the general population. International Journal of Methods in Psychiatric Research, 8(2), 110-122. doi:10.1002/mpr.61

Ruganci, R. N., \& Gencoz, T. (2010). Psychometric properties of a Turkish Version of the Difficulties in Emotion Regulation Scale. Journal of Clinical Psychology, 66(4), 442-455. doi:10.1002/ jclp. 20665

Salguero, R. A. T., \& Moran, R. M. B. (2002). Measuring problem video game playing in adolescents. Addiction, 97(12), 1601-1606.

Savci, M., \& Aysan, F. (2016). The role of attachment styles, peer relations, and affections in predicting Internet addiction. Addicta-the Turkish Journal on Addictions, 3(3), 416-432. doi:10.15805/addicta.2016.3.0028

Schimmenti, A., Guglielmucci, F., Barbasio, C., \& Granieri, A. (2012). Attachment disorganization and dissociation in virtual worlds: A study on problematic Internet use among players of online role playing games. Clinical Neuropsychiatry, 9(5), 195-202.

Schimmenti, A., Passanisi, A., Gervasi, A. M., Manzella, S., \& Fama, F. I. (2014). Insecure attachment attitudes in the onset of problematic Internet use among late adolescents. Child Psychiatry \& Human Development, 45(5), 588-595. doi:10.1007/s10578-013-0428-0
Schore, A. N. (2016). Affect regulation and the origin of the self : the neurobiology of emotional development. New York, NY: Routledge.

Schreiber, L. R. N., Grant, J. E., \& Odlaug, B. L. (2012). Emotion regulation and impulsivity in young adults. Journal of Psychiatric Research, 46(5), 651-658. doi:10.1016/j. jpsychires.2012.02.005

Selcuk, E., Gunaydin, G., Sumer, N., \& Uysal, A. (2005). A new measure for adult attachment styles: The psychometric evaluation of Experiences in Close Relationships - Revised (ECR-R) on a Turkish sample. Turkish Psychological Articles, 8, 1-11.

Severino, S., \& Craparo, G. (2013). Internet addiction, attachment styles, and social self-efficacy. Global Journal of Psychology Research, 1, 9-16.

Shaffer, H. J., Hall, M. N., \& Vander Bilt, J. (2000). "Computer addiction": A critical consideration. American Journal of Orthopsychiatry, 70(2), 162-168. doi:DOI 10.1037/h0087741

Shin, S. E., Kim, N. S., \& Jang, E. Y. (2011). Comparison of problematic Internet and alcohol use and attachment styles among industrial workers in Korea. Cyberpsychology Behavior and Social Networking, 14(11), 665-672. doi:10.1089/ cyber.2010.0470

Siddiqui, J. A., Qureshi, S. F., \& Alghamdi, A. K. (2018). Internet gaming disorder: A case report. Journal of Behavioral Health, 7(1), 43-46. doi:10.5455/jbh.20170928054951

Siegel, D. J. (2012). The developing mind : How relationships and the brain interact to shape who we are (Second Edition ed.). New York, NY: Guilford.

Spada, M. M. (2014). An overview of problematic Internet use. Addictive Behaviors, 39(1), 3-6. doi:10.1016/j. addbeh.2013.09.007

Spada, M. M., Langston, B., Nikcevic, A. V., \& Moneta, G. B. (2008). The role of metacognitions in problematic Internet use. Computers in Human Behavior, 24(5), 2325-2335. doi:10.1016/j.chb.2007.12.002

Spada, M. M., \& Marino, C. (2017). Metacognitions and emotion regulation as predictors of problematic Internet use in adolescents. Clinical Neuropsychiatry, 14(1), 59-63.

Starcevic, V. (2010). Problematic Internet use: a distinct disorder, a manifestation of an underlying psychopathology, or a troublesome behaviour? World Psychiatry, 9(2), 92-93.

Starcevic, V. (2013). Is Internet addiction a useful concept? Australian and New Zealand Journal of Psychiatry, 47(1), 16-19. doi:10.1177/0004867412461693

Suissa, A. J. (2015). Cyber addictions: toward a psychosocial perspective. Addictive Behaviors, 43, 28-32. doi:10.1016/j. addbeh.2014.09.020

Taheri, M., \& Irandoust, K. (2018). The exercise-induced weight loss improves self-reported quality of sleep in obese elderly women with sleep disorders. Sleep and Hypnosis, 20(1), 54-59. doi:http://dx.doi.org/10.5350/Sleep.Hypn.2017.19.0134

Tao, R., Huang, X. Q., Wang, J. N., Zhang, H. M., Zhang, Y., \& Li, M. C. (2010). Proposed diagnostic criteria for internet addiction. Addiction, 105(3),556-564.doi:10.1111/j.1360-0443.2009.02828.x

Tokunaga, R. S. (2015). Perspectives on Internet addiction, problematic Internet use, and deficient self-regulation: Contributions of communication research. In E. L. Cohen (Ed.), Communication yearbook (Vol. 39, pp. 131-161). New York; NY: New York: Routledge.

Tokunaga, R. S. (2017). A meta-analysis of the relationships between psychosocial problems and internet habits: Synthesizing internet addiction, problematic internet use, and deficient self-regulation research. Communication Monographs, 84(4), 423-446. doi:10. 1080/03637751.2017.1332419 
Tokunaga, R. S., \& Rains, S. A. (2010). An evaluation of two characterizations of the relationships between problematic Internet use, time spent using the Internet, and psychosocial problems. Human Communication Research, 36(4), 512-545. doi:10.1111/j.1468-2958.2010.01386.x

Ulusoy, M., Sahin, N. H., \& Erkmen, H. (1998). Turkish version of the Beck Anxiety Inventory: Psychometric properties. Journal of Cognitive Psychotherapy, 12(2), 63-172.

Üstün, T. B., Kostanjsek, N., Chatterji, S., \& Rehm, J. (2010). Measuring health and disability: Manual for WHO Disability Assessment Schedule (WHODAS 2.0). Malta: World Health Organization.

van den Eijnden, R. J. J. M., Meerkerk, G. J., Vermulst, A. A., Spijkerman, R., \& Engels, R. C. M. E. (2008). Online communication, compulsive Internet use, and psychosocial well-being among adolescents: A longitudinal study. Developmental Psychology, 44(3), 655-665. doi:10.1037/00121649.44.3.655

Vandelanotte, C., Sugiyama, T., Gardiner, P., \& Owen, N. (2009). Associations of leisure-time Internet and computer use with overweight and obesity, physical activity and sedentary behaviors: cross-sectional study. Journal of Medical Internet Research, 11(3). doi: 10.2196/jmir.1084

Yang, X. J., Zhu, L., Chen, Q., Song, P. P., \& Wang, Z. H. (2016). Parent marital conflict and Internet addiction among Chinese college students: The mediating role of father-child, motherchild, and peer attachment. Computers in Human Behavior, 59, 221-229. doi:10.1016/j.chb.2016.01.041
Yen, J. Y., Yeh, Y. C., Wang, P. W., Liu, T. L., Chen, Y. Y., \& Ko, C. H. (2018). Emotional regulation in young adults with Internet gaming disorder. International Journal of Environmental Research and Public Health, 15(1). doi:10.3390/ijerph15010030

Yen, J. Y., Yen, C. F., Chen, C. C., Chen, S. H., \& Ko, C. H. (2007). Family factors of Internet addiction and substance use experience in Taiwanese adolescents. Cyberpsychology \& Behavior, 10(3), 323-329. doi:10.1089/cpb.2006.9948

Yildiz, M. A. (2017). Emotion regulation strategies as predictors of internet addiction and smartphone addiction in adolescents. Journal of Educational Sciences \& Psychology, 7(1), 66-78.

Young, K. (1998). Caught in the net. New York, NY: Wiley.

Young, K. S. (1998). Internet addiction: The emergence of a new clinical disorder. Cyberpsychology \& Behavior, 1(3), 237-244. doi:10.1089/cpb.1998.1.237

Yu, J. J., Kim, H., \& Hay, I. (2013). Understanding adolescents' problematic Internet use from a social/cognitive and addiction research framework. Computers in Human Behavior, 29(6), 2682-2689. doi:10.1016/j.chb.2013.06.045

Zhou, Y. Y., Li, D. P., Li, X., Wang, Y. H., \& Zhao, L. Y. (2017). Big five personality and adolescent Internet addiction: The mediating role of coping style. Addictive Behaviors, 64, 42-48. doi:10.1016/j.addbeh.2016.08.009 